\title{
IDENTIFYING BOTTLENECKS IN WORK PROCESSES: ELDERLY CARE
}

\author{
Hanna-Leena Huttunen \\ Empirical Software Engineering in \\ Software, Systems and Services, M3S \\ University of Oulu \\ Oulu, Finland \\ hanna-leena.huttunen@oulu.fi
}

\author{
Raija Halonen \\ Empirical Software Engineering in \\ Software, Systems and Services, M3S \\ University of Oulu \\ Oulu, Finland \\ raija.halonen@oulu.fi
}

\author{
Denzil Ferreira \\ Center for Ubiquitous Computing \\ University of Oulu \\ Oulu, Finland \\ denzil.ferreira@oulu.fi
}

\begin{abstract}
This paper investigates the challenges of elderly care from the perspective of caregivers. More concretely, we identify caregivers' workflows and pinpoint the main bottlenecks in a sheltered accommodation. As the general population is aging fast, the role of information and communication technology (ICT) has grown in importance for elderly care. This development has brought versatile ICT-related supportive systems to caregivers and laymen working with aging people. Our study first analyzed how professionals in elderly care perceived their workflow challenges. A new ICT system was developed and implemented to support their work. The results of our study inform the design of upcoming ICT systems for a sheltered accommodation that are in high demand today.
\end{abstract}

Keywords-elderly care; bottlenecks; workflows; sensors; healthcare; Sheltered accommodation

\section{INTRODUCTION}

The population is aging fast. The amount of people older than 60 years was 868 Million in 2015 it is expected to be more than 2 billion in 2050, where 33 countries in Europe and Asia have more people $65+$ years than under 15 years old [1]. The purpose of our study is to find out how caretakers working in elderly care perceive their current work processes and future challenges at work. The study was carried out in a sheltered accommodation in Northern Finland.

The motivation of the research was the growing number of elderly people in the world and the increased need for care in health care and social care units that provide care to the end of the life cycle. The need for care for residents of sheltered accommodation is based on proactive decisions and a care and service plan [2]. By identify the bottlenecks in care services one can improve the quality of care provided by nursing staff through the use of healthcare technology. ICT can improve the quality of life and well-being of residents and nurses. Health Technology Assists Residents in Physical, Psychological and Social Welfare [39]. The means of ICT has influenced everyday life and enhanced service quality in many ways. One significant sector where Information and Communication Technology (ICT) has brought successful solutions, is the health sector [3].
ICT appears in the health sector in many forms. These forms can be divided into four broad categories; management systems, communication systems, computerized decision support systems and information systems.

In this study, we aimed at better understanding of sheltered accommodation workflows and identify care workflow bottlenecks in order to create an Internet of Things (IoT) infrastructure, called CARE, following a User-Centered Design approach [12]. The focus was on daily challenges, routines and concerns in daily work of sheltered accommodation nurse's. The research question was answered through focus group interviews and observations. Sheltered accommodation nurse's were met several times during the study.

The study is part of the CARE research programme and aims to understand the workflows and bottlenecks in service accommodation. By means of ICT, we can encourage the elderly to live a life of high quality, facilitate the work of nursing staff and bring resident's relatives to part of care. The study will continue to the next stage in which the field study will be described in detail. The paper ends in a conversation that reflects the results of earlier research. 17 bottlenecks were identified and those will being studied in more detail.

\section{RELATED WORK}

\section{A. Sheltered accommodation}

The population is getting older rapidly and the costs of aging care are known to rise globally by about $14.58 \%$ by 2060 [13]. Expenditure of elderly people is known to rise by about 3 to 5\% in the European Union by 2050 . Covering and mitigating this rise is one of the most important development targets in Europe over the coming decades. Usage of sheltered accommodation has risen since 21 st century and it is considered to be better than institutional care for elderly who cannot live in own house. Population aging and service needs mean that the service system needs to be reformed and evaluated by existing practices, and involve assistive technology (AT) in resident care processes $[2,6$.$] . The role and concept of 'user' is significant$ when studying and implementing information systems design [14]. 
Quality of care and service for older people can only be based on a carefully assessed overall situation. [15]. Resident Assessment Instruments (RAI) is a standardized assessment, monitoring, and quality improvement system for care and services and it is aimed at assessing the resident's service needs and developing a treatment, rehabilitation and service plan. $[16,17] \mathrm{RAI}$ is the future of nursing and it is constantly being developed and expanded into a variety of nursing tools. $[16,17,30]$. Different RAI systems have been developed to be compatible with each other, resulting in high quality workflow processes. The RAI assessment system should be used whenever a resident is registered with the hospital and again at most every half a year. The resident's care needs are met by taking advantage of his remaining resources, assisted by nursing staff with skill in the field. [16,27].

The RAI evaluation system consists of two basic components. These parts are the Minimum Data Set (MDS), the minimum amount of data needed, and the Residential Assessment Protocol (RAP), which is an aid to make an individual nursing plan. The objective of the RAI assessment system is to gather information on the residents in multiprofessional cooperation in an electronic MDS file and serve as a basis for evaluating the need for care of a resident. RAP prints out the strengths, risk factors and problem challenge areas of the resident. The RAP list uniquely addresses the oneinhabitant problem areas and thus serves as the basis for an individual care and service plan. [31] The assessment focuses on the following areas: cognitive ability, communication, hearing, vision, mood and behavior, psychosocial wellbeing, physical function, retention, diagnosis, health, oral health and nutrition, teeth, skin condition, activity and activity, medication and special treatments nurses' rehabilitation. The RAI assessment is carried out by the homeless person in cooperation with the nursing team [27].

In addition to the elderly and his relatives social work, health care staff, medical practitioner bring together their expertise to provide timely and accurate services to the needs of older people and are involved in the assessment. The aim of the assessment is to create a problem-free service package that corresponds to the resident's needs and changing operational capability, which changes according to changes in the resident's operational capability. Decreasing of performance of elderly because of aging and long-term illnesses happens gradually [15].

The deterioration of capacity is divided into four different areas. The first step is the AADL (Advanced Activities of Daily Living), where social activities decreases. The problems in the second phase (IADL: Instrumental Activities of Daily living) are problems with usage of everyday devices, such as cleaning, telephone use, or bank account management. In the third stage, the deterioration of functional capacity (BADL or ADL: Basic Activities of Daily Living) extends to the deterioration of dayto-day basic functions that have been deteriorated in the following order: walking, washing, getting up and moving from bed and chair, dressing, going to the toilet, eating and drinking, remembering the daily dose of medicine, and handling things [27].

\section{B. Wireless sensors in healthcare}

ICT enables more sophisticated sensor technology for healthcare. The sensor network consists of sensors designed to monitor the environment and transmit the information it collects in digital form forward. [22,23,24]. Healthcare sensors are integrated into devices, systems, and environments. [22,24] In the future, implement more effective solutions must be implemented for the elderly, as health in Finland, Europe and the United States is decreasing all the time. Sensors are used in home care, where they provide important information about residents' physiological, physical and cognitive health. This information is necessary to evaluate the patient's condition, determine the diagnoses and make treatment decisions and follow-up plans. [22,24,25] Moreover, the development of IoT has provided new possibilities to benefit sensor-based technology [26].

Most of today's patient monitoring is possible to do with sensor technology; thermometers, blood pressure monitoring devices, blood glucose monitoring devices, electrocardiographs (EKG) as well as numerous imaging technologies are transferred to information systems through the network. [22]. In healthcare, sensor technology is used at detecting the patient's state of health by, for example, electronic, thermostatic, optical, chemical, genetic signals. These signals, combined with algorithms developed for technology, provide information on the individual's personal status and enable the medical staff to receive information more efficiently. Also, sensors that do not directly measure the health of a person are also widely used in health care. These include, for example, technologies for positioning and logistics, which can be used to improve the availability of care. [22,24].

The development of health technology enables the quality of life of aging people to be improved and provides a wide range of tools for interaction between the elderly and nursing staff. Technological impacts can be studied broadly, as technology has the potential to come into contact with all four aspects of quality of life: physical and psychological wellbeing, maintaining social relationships, and the environment. [39]. In all, technology can improve the quality of life by providing new ways of communicating and managing things to sheltered accommodation clients and nursing staff.

\section{Smart home in the elderly care}

The development of sensors and their potential for versatile sensing have increased greatly in recent years. Cheap, compact and technically high quality sensor solutions have made it possible for wireless sensor networks to be used in people's daily lives [23].

The benefits of a comprehensive healthcare system enabled by wireless sensor networks are also the ability to identify contexts. Context awareness helps us understand the people being monitored and their habit. [22,24]. By simultaneously 
sensing the body's functions, activity and positioning, one can draw far-reaching conclusions about the health of the elderly.

In most of today's applications, the sensors are attached to the target's body or clothes, forming a Body Area Network (BAN). Such sensors measure, among other things, the heart's heart rate and overall movement. For ease of use and free movement, the sensors and other components of the system should be as discreet as possible so that their existence does not affect the target's everyday life. There are problems with security in terms of availability of information and security of information. Information gathered by the system should be widely available, especially in critical healthcare applications, such as rollover detection. [8]

The part of the system where the sensors are located near the target is called the Personal Area Network (PAN) network. The sensors can be placed in a person's home or can be placed in moving objects such as small home objects or even a person's smartphone. Generally, the PAN network sensors measure motion, sound, air pressure, temperature, humidity or, for example, the amount of light. The common goal of these sensors is to gather important additional information about the target person and his environment $[22,40]$.

The gateway is responsible in the wireless sensor network to connect BAN and PAN networks to the Wide Area Network (WAN) network. Depending on the system, the WAN network may mean either a cellular network, an ordinary telephone network, a satellite network or an Internet network. Gateway can be a portable mobile device. Because the gateway acts as a link between the sensors and the WAN, it is commonly seen as the weakest link in wireless sensor networks. Therefore, it is important that BAN and PAN networks are able to process as much information as possible in order to minimize the amount of data to be transmitted through Gateway. [22,4,41]

When considering ICT-based information system, a continuing user support and user-friendly user interface that is to decrease the amount of manual tasks [32]. The concept of 'a user' can be characterized by affiliations, environments, interactions, and identities. In the characterization, affiliation is shaped by organizational level relationships; environments consist, e.g., network of relationships in the organization; interactions include packages of information, resources and media; and identities represent the selves that are exchanging information in the organization. [14]

\section{RESEARCH METHODOLOGY}

Qualitative research is valid especially in cases when social phenomena are in focus and when the empirical research consists of interviews [35]. According to [43], all material collected by the researchers can be considered as a significant data that can help in solving the research problem, and the research question usually leads to choose the relevant research method. User-centered design is a valid approach especially in cases when users are encouraged to add understanding the user requirements, and its multidisciplinary nature allows several means to collect research data [12]. The role of social skills of the researcher are emphasized as the researcher needs skills to build and maintain social contacts during the research [36]. As a method of letting informants describe their experiences and thoughts, narrative approaches have been used. However, a narrative approach can also provide possibilities to have selfcritical perspective for the informants. [33] Focus group interviews are used to find out the views and understanding of nursing staff and is a very common research method in the field of drug research. They are carried out as a discussion in a selected group and conducted by the interviewer on the basis of a predetermined interview body. It is a qualitative research method that seeks to understand the phenomenon being studied. Generally the size of the group is $4-10$ people and usually interviews lasts 45 minutes. Processes guide conversations by keeping them in the thematic topic [42].

\section{Research context}

The empirical research was carried out among the staff of the enhanced service area of Northern Finland and its residents. The selection criterion was that the participants had to have work experience in sheltered accommodation workflow processes. The group was selected discreetly but ensuring that the selector of the interviewees knew that the group had several years of work experience in service housing. The interviews were carried out with a Focus Group Interview approach encouraging innovative discussion and open atmosphere.

\section{E. Collection of empirical material}

The research was of qualitative in nature due to the low level of reported bottlenecks caused by the workflows of sheltered accommodation. The target group of the survey was the nursing staff of sheltered accommodation. The material was collected through a Focus Group interview in December 2017. The questions were drawn up on the basis of a literature review that created themes for a group interview. The interview consisted of six themes: familiarization with resident prior to entering the unit, resident reception, care and service plan, resident relationship development, client death, patient relatives, and end of resident relationship. Open-ended questions were used in every topic of the survey, and each theme was approached with the same questions (see Table 1). The nurses were asked to describe what steps were included in the process when a new resident was to move in the unit, to name process partners, what factors influence the smoothness of the process, what problems they were experiencing in the process, how technology could develop this process and what kind of technology they would like to use in the process. Focus group interviews were arranged during shift change, thus securing the number of nurses in the service. The interviews lasted for a total of 45 minutes, and they gave rise to creative and fruitful discussion.

TABLE I. TOPICS DISCUSSED WITH OPEN ENDED QUESTION.

\begin{tabular}{|l|}
\hline What kind of steps are included in this process? \\
\hline What kind of people are involved in this process? \\
\hline What factors influence the fluency of the process? \\
\hline
\end{tabular}


What kind of problems did you notice during the process

How could technology develop or improve this process in your unit?

\section{F. Analysis of data}

Focus grouping is intended to create new ways of working based on current practices but will seek to change them in the future. The material was analyzed by categorizing a focus group interview according to the treatment processes. The interviews were recorded and transmitted for analysis. Tone of speech were not marked, but long breaks, superimposed speech, unclear words and nausea, screams were labeled with appropriate labels for littering [44]. Initially, the data was carefully examined by listening to the tape several times and recording notes. The material was analyzed theoretically by content analysis, which is described by the processes of the service platform (the processes presented earlier) and serve as a framework for analysis by guiding nursing processes and bottlenecks from them. The material was read several times to get an overall picture and was tabulated. Responses were sought for the material, organized into categories and named in accordance with the content. The classes were summarized and combined according to the processes. The description of the material was used for the tables and direct quotations.

The interview consisted of six themes, which were the familiarization with resident prior to entering the unit, the resident's reception, the care and service plan, the resident relationship development, the client's death, and the termination of the relationship.

\section{RECOGNIZE BOTTLENECKS IN WORK PROCESS}

\section{G. Familiarization with resident prior to entering the unit}

The interviewees revealed what happens before a new resident moves in: A multi-professional team decide that a resident should be moved to the waiting list for the supported care when the resident was not able to live independently at home. The relatives visit the houses and health care personnel describe their services to them. If the relatives accept the supported housing, they agree that their elderly will move to the sheltered accommodation.

In the interviews it appeared that the personnel were not informed enough before the new resident arrived. The elderly might have been in several care homes before entering to the current place, and the information about those periods is not available when the elderly moves in. There usually was no information about the elderly - if she or he was able to walk or if any assisting tool was needed; if the elderly was able to use toilet or wash independently; what medication was in use; and what kind of personality was existent. The personnel thought that often significant information was not shared, and it could affect the given care. Furthermore, the relatives were quite active in the early times of the new caring environment and they actively participated in the care. However, the information received from the relatives was often insufficient. Often, the relatives cannot tell about the capability of their elderly - if and how they move, if there are assisting tools in use, how does the elderly manage in toilet, or if the elderly has any specific personality or not. The care personnel wanted more information sharing in the phase when the residents are entering the care. The personnel thought that the information could ease collaboration between the personnel and the relatives.

\section{H. Resident's reception}

The relatives make decisions about the transition of their elderly to the care. The personnel welcome the elderly and they show the home to the new resident. (see Figure 1). The nurse in charge writes an agreement of renting with the relatives and takes care of agreements with the Pharmacy. The relatives bring some personal items of the elderly and they furnish the room to remind a home. In addition, they provide a written history of the life of their elderly, and the document is stored in a file. The nurses read the personal files if they want additional information about the new resident.

The nurses get to know the new resident and seeks to identify important details of the resident's past life and to bring them part of the nursing home. Including a new resident in to the daily life of the service room is important that resident does not remain in own room and suffer from loneliness. It is important for a resident to have a good and reliable care relationship at this stage. 


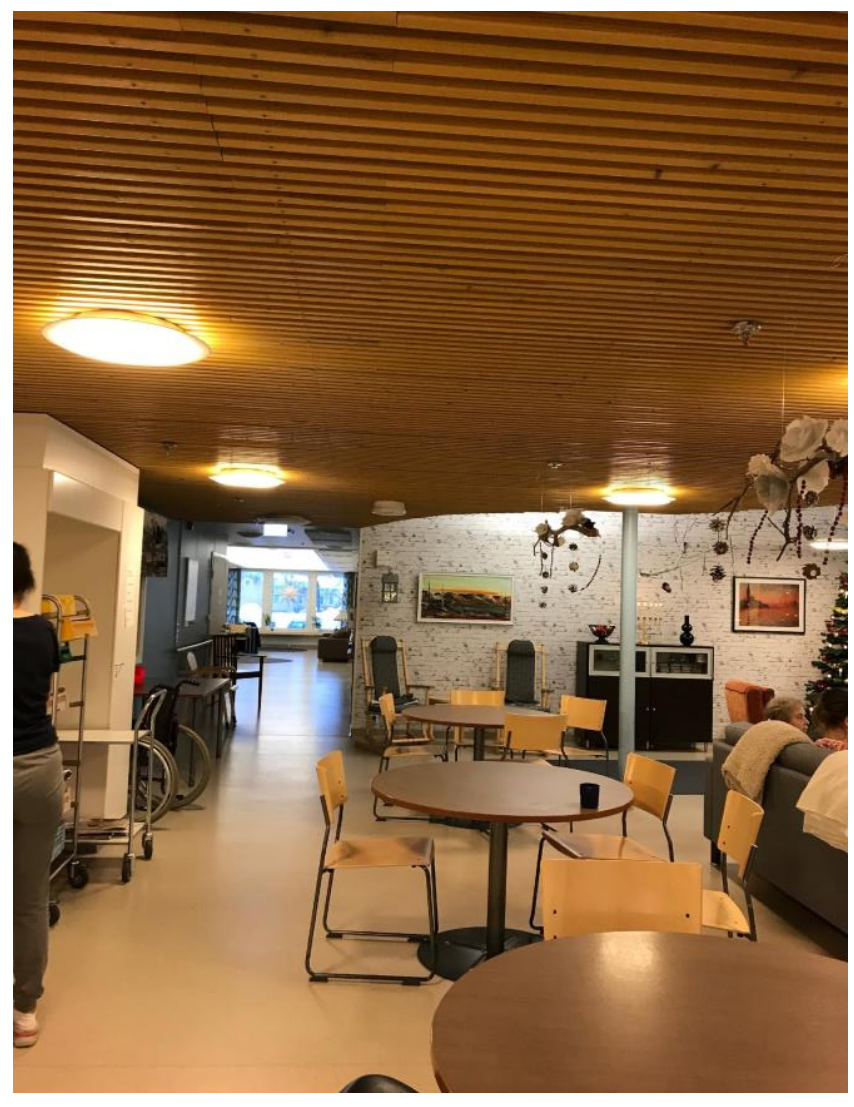

Fig. 1 Sheltered accommodation common premises

\section{Care and service plan}

A care and service plan was made in collaboration with the resident or family members. The care and service plan compiles information on all the health problems of the client as well as the planned care studies and medical rehabilitation for the resident. The care and service plan should always record the patient's diagnosis, the need and goal of care, the division of labor, the implementation and means of treatment, the monitoring and evaluation, and the client's medication. The care and service plan also includes the support given by relatives in the resident's daily activities.

The care and service plan directs nurses to take care of the client to cope with daily activities such as sensory functionality and activity, medical treatment, washing, dressing, eating and drinking, movement, special function, sleeping and rest, social needs (family, friends), spiritual needs and mood and intimacy. It is easy for nurses to follow the guidance and help functions when working together with the client to maintain self-reliance, independence and ability to function is supported by enabling residents to attend nursing careers. Technology helps nurses identify residents' needs and goals and help methods when they are available in real time near nurses. Nurses is no need to check resident data from the office, when data is available all the time.

The nursing staff wrote a care and service plan on paper and put the document to the resident's personal folder. (see Figure 2). The nursing home had a health care management system but they do not actively use it. Every two weeks, the resident's care was recorded in the information system. Nurses wrote if nurses wanted to check the patient care plan, they would look at the resident's own folder.

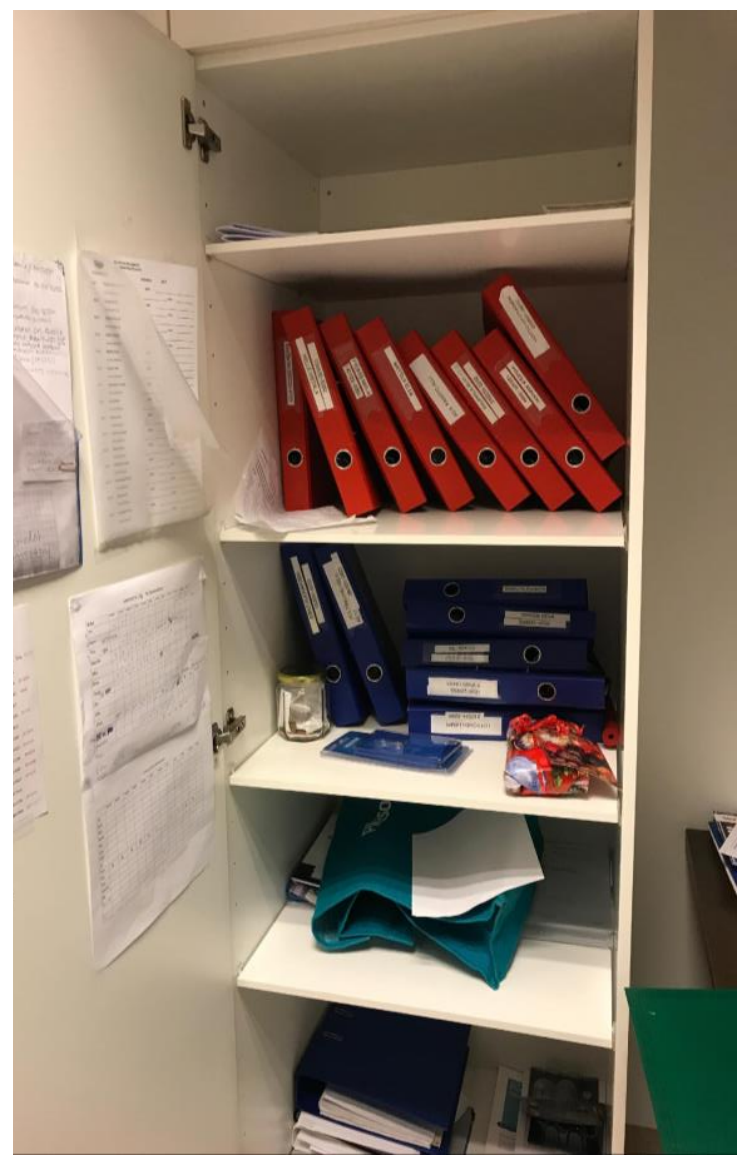

Fig. 2. Care and service plan folders in the closet

The care workers operate in three shifts: Morning shift (07:00 - 15:00) day shift (13:00-21:00), and night shift (20:30 07:00). The nurses kept the report every day from 13:00 to 14:00. They discuss the residents status during the past day. When nurses give report they don't have any notes. There are four nurses present during the morning and day shift and only one working during nights and weekend. Workload is highest in morning shift. Daily routines follow flexible schedule and 
morning tasks starts when the resident wakes up. Morning tasks includes measuring of pulse, temperature, blood pressure, blood sugar, weight and blood test. The resident is helped to go to the morning shower and after that is breakfast.

The medication for the resident is based on the individual prescription and they are acquired from the Pharmacy. In the sheltered accommodation, a nurse divides the medication into a pill dispenser for a week. This procedure was changed only shortly, which had caused additional workload for the nurses. Figure 3 shows portion bags that arrive as portioned from the Pharmacy. The nurses experience the bags loading if there are changes in the medication. The portion bag includes daily medication for a patient, and the bags are marked as 'morning 8:00', 'day 12:00', 'evening 16:00' and 'night 20:00'. If there are changes in medication, there are no medication available in time and one does not easily recognize the medication if the bags look similar. The nurses experience that it is loading to break the bags and that the pills are challenging to identify. Earlier the pills were placed in a locked closet in the home, and it was easy to change them. Currently, every resident receives portioned medication bags once a week. In case of changes, the nurse must phone to the Pharmacy and ask to change the bags. It appeared that there is a significant bottleneck in medication because the nurses have no competence and knowledge about new medication. The help of information systems was perceived beneficial when changes with medication are at hand. In that case, the change in medication is known real-time in the Pharmacy, and the Pharmacy can acknowledge the medication change to the care personnel. With the assisting technology also family members get to know changes in medication and they can ask further information from the care personnel.

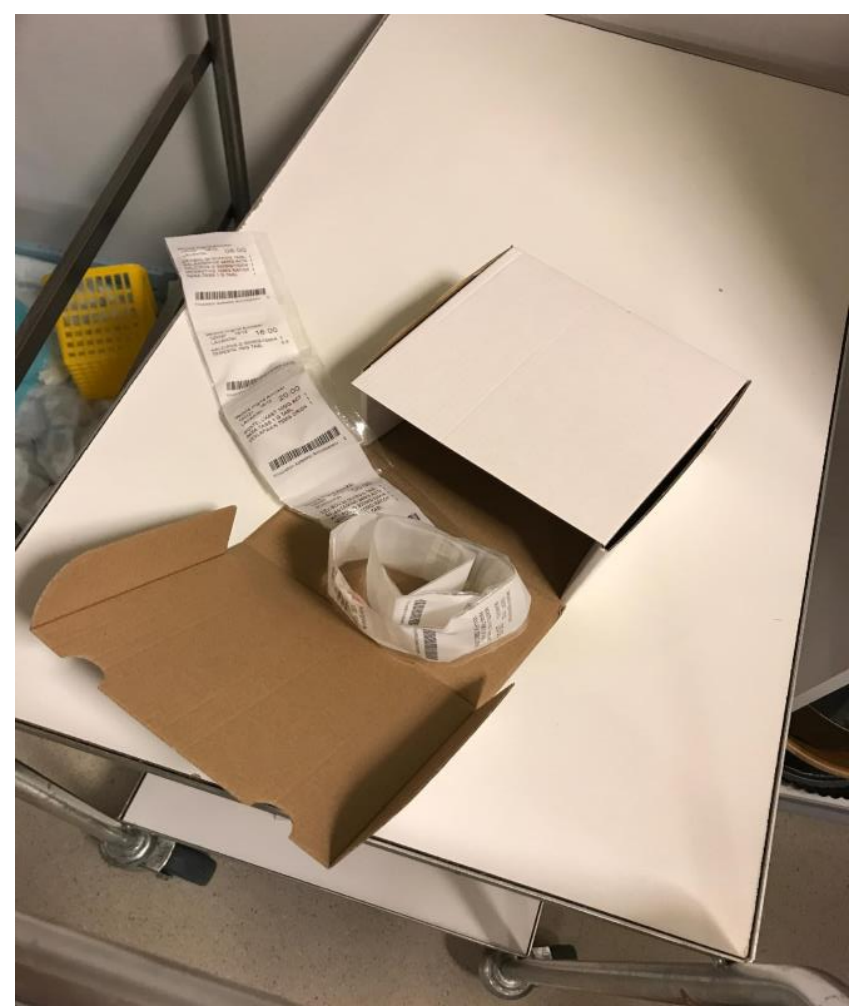

Fig. 3. Resident medicine backs

\section{J. Resident's death}

In the latest days of the elderly the condition and movement of the resident fail, and the resident loses appetite and will to have anything to drink. At the same time, swallowing gets more difficult and the elderly get sleepier. In this phase, the caring personnel need empathy and skills to see the oppression and distress of the family members. More than caring for the disease it is important to consider the wellness of the resident and emphasize the importance of painlessness. The personnel informs the relatives about the condition of their elderly and what kind of medication is in use. They also find out if the relatives need support or assistance due to the near death of their elderly. After the death has taken place, the personnel contacts medical doctors to state officially the death. After that, the relatives make arrangements with a funeral parlor.

\section{K. Termination of the relationship}

A good and constructive final evaluation releases the worker from the inadequacy and dependence of the feelings and experiences that are generated in the elderly. Resident information, as well as a care and service plan, will be kept in the archives as long as the relationship lasts. They will then be archived in accordance with the archives and local archive plan and agreements. Documents (see Figure 4) that are not justified on retention shall be destroyed by chopping or burning. 


\section{DISCUSSION}

This study identified the resident's steps in the sheltered accommodation. These include tasks before the resident enters the unit, receiving the resident to the facility, drafting a care and service plan, resident death, paying attention to the clients' relatives, and ending the care relationship. As part of the wider research, the aim was to find out if bottlenecks can be identified from the phases of nursing. A wider project explored whether bottlenecks caused by nursing could be detected by utilizing intelligent systems, fixed sensors, or wearable sensors. The study showed that bottlenecks are present at each stage, affecting the ability of relatives and nurses to handle the resident better. With sensor technology, we can improve the quality of life of a resident. Researchers [15] note in their research that quality care and service housing can only be based on a carefully assessed overall situation. Resident performance is evaluated with a multi-professional team. In addition to the elderly and his or her relatives, social work, health care staff, and medical practitioner participate in the assessment.

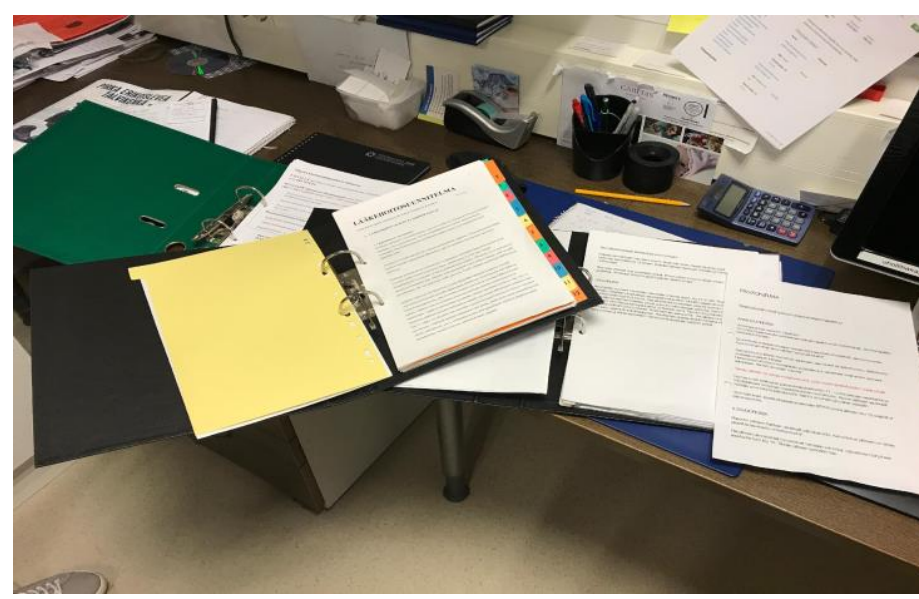

Fig.4. Resident files.

Researchers [22] presents in their research, applications where sensors are attached to the target's body or clothing (BAN-network). Sensors that can be attached to the body can measure, for example, the heart rate and overall movement. In terms of ease of use and the free movement of the elderly, the sensors of the system should be as unobtrusive as possible so that their existence does not affect the everyday life of the target person and the nursing staff's nursing service. It is also possible to locate sensors closely to the elderly (PAN-network), which are fixedly attached to a person's dwelling or can be placed in moving objects such as home objects or roller. The common goal of these sensors is to gather important additional information from the target person and his or her environment and to transmit the health information of the resident to the nursing staff and their relatives.

Researches [45] states that doctors and nurses benefit from the patient's ongoing biosignal data collection. In addition, the benefits of sensors help patients to identify their physical and psychological activity [40]. In recent years, intelligent healthcare systems have been raised as one of the most important research topics and health data is being monitored and stored more and more in health care (see [41]). The earlier studies reveal that in sheltered accommodation work processes can be supported by sensor technology. Thus the nurses can use their time for the caring tasks. With sensor technology, the physical, psychological and social changes can see observed in time, if the sensor-based data are monitored. In future, the healthcare services will change towards digital services, and with the ever-changing technology. In addition, the information can be available quickly or in real time.

Technology can assist the care personnel to manage with elderly who are not sick and nurses can concentrate on sick patients. The current study was implemented among personnel in a home that provided supportive accommodation for elderly, and the target group was rather small. However, the study was able to identify 17 bottlenecks, and they were found by interviewing and observing in the home.

The study revealed that some of the interviewees with medical education were against assisting technology in the beginning, but in the interviews, they told that they need technology almost every day at work. The nurses confessed that the law and regulations require daily registration for the health records of the residents, however the procedure was not followed in this care unit.

This special phase revealed several bottlenecks that were identified based on the interviews and observations. These include the transfer of information from the previous treatment center to the unit, the relatives' ignorance of the treatment measures and the unregistered healthcare information system. The law obliges the resident of the service house to be evaluated every six months and for this purpose a RAI valuation has been developed, which is a standardized comprehensive assessment, monitoring and updating and quality improvement scheme for care and services. The purpose of RAI is to evaluate the service needs of the client, as well as a tool for developing a treatment, rehabilitation and service plan that is used worldwide in the care of the [16,17]. The information provided by RAI and information transfer facilitates the medical staff to familiarize themselves with the patient and to care for him better. The information provided by the sensors enables the data to be stored directly into the information system and can be utilized to evaluate the physical, psychological and functional capacity of the client. The researchers point out a total of 17 bottlenecks in Table 2. 
TABLE II.

BOTTLENECKS IN SHELTERED ACCOMMODATION

\begin{tabular}{|l|}
\hline Nurses don't write down patient vital health \\
\hline When nurses give report they don't have any notes \\
\hline Nurses use paper and pencil for notes \\
\hline Nurses don't know how long patients sleep in the room \\
\hline Nurses don't know if patient is sick \\
\hline Nurses don't know about activity change \\
\hline $\begin{array}{l}\text { Nurses have to visit every patient room and ask how are you } \\
\text { or how is you mood today }\end{array}$ \\
\hline $\begin{array}{l}\text { Nurses don't know how long patient have waited for } \\
\text { morning/evening shower }\end{array}$ \\
\hline $\begin{array}{l}\text { If patient use diapers, nurses don't know when diaper has } \\
\text { been changed and when to change new }\end{array}$ \\
\hline Family doesn't know anything about patient daily routine \\
\hline Nurses checks paper list of daily tasks what to do with patient \\
\hline $\begin{array}{l}\text { New nurses don't know about patients when she/he starts } \\
\text { work. No introduction album about patients }\end{array}$ \\
\hline Nurses don't know if patient is out of bed. Risk of accidents \\
\hline Nurses shout to get help from each other \\
\hline $\begin{array}{l}\text { Doctor gets information from note book where nurses write } \\
\text { down patients problems }\end{array}$ \\
\hline Every two weeks doctor visit in elderly care home \\
\hline Healthcare technology is not used \\
\hline
\end{tabular}

\section{CONCLUSIONS}

As a conclusion one can propose that the preliminary results are promising and, that they realize the willingness of the care personnel to use assisting technology in identifying existing bottlenecks in the care. The physical, psychic and functional wellness can be promoted with the help of smart systems. In future, smart sheltered accommodation will be everyday life in developed countries. Versatile smart device and systems will support the care personnel and decrease bottlenecks in work processes. With increasing health technology, the intelligence of device has emerged, the technology is smarter than earlier, and the prices are coming down. An intelligent device releases hands to be used in pure care. In future, health technology can be built in the houses as part of the care work.

The ICT helps doctors to treat patients with higher quality and gives nurses more time to take care of patients. The study focus group interviewed care personnel of sheltered accommodation, and even the interviewee target group was rather small, every nurse identified bottlenecks from workflows. One of the biggest bottlenecks is that the nurses write only very little information about resident care, functionality or mental health to information system.

On the other hand, technology can weaken efficiency of people who cannot adopt required technical skills to be used in care work. In Finland, there is currently no abundance of studies about improving quality of life of the elderly with means of technology.

Furthermore, work processes in sheltered accommodation have received only little attention in earlier studies, even if the topic is significant in providing high quality care. Measuring and controlling health status of elderly has become popular due to new sensor technology and wireless data transfer [23].

The current study revealed that the care people are ready to adopt assisting technology in different phases of their care work.

\section{ACKNOWLEDGMENT}

This work is partially funded by the Academy of Finland (Grants 286386-CPDSS, 285459-iSCIENCE, 304925-CARE, 313224-STOP), and Marie Skłodowska-Curie Actions (645706-GRAGE).

\section{REFERENCES}

[1] Bureau. (2017). Population Reference Bureau. Accessed December 28,2017: http://www.prb.org/Publications/DataSheets/2016/2016-worldpopulation-data-sheet.aspx

[2] Antolín, P., H. Oxley and W. Suyker (2001), "How Will AgeingAffect Finland?", OECD Economics Department Working Papers, No. 295, OECD Publishing, Paris. http://dx.doi.org/10.1787/361422456778

[3] Sein, M. K., \& Harindranath, G. (2004). Conceptualizing the ICT artifact: Toward understanding the role of ICT in national development. The Information Society, 20(1), 15-24.

[4] Alemdar, H., JA Ersoy, C. Wireless sensor networks for healthcare: A survey. Computer Networks 54, 15 (2010), 2688 - 2710

[5] UN. (2015). United Nations, Department of Economic and Social Affairs, Population Division. World Population Prospects: The 2015 Revision, Key Findings and Advance Tables. Working Paper No. ESA/P/WP.241.

[6] Cook, G. A., Bailey, C., \& Moyle, W. (2013, June). The impact of ICTbased telecare technology on quality of life of people with dementia: Review of the literature. In Human System Interaction (HSI), 2013 The 6th International Conference on (pp. 614-619). IEEE.

[7] Hellstén, K., 2014 WORK-RELATED PHYSICAL AND PHYCHOLOGICAL STRESS IN ELDERLY CARE - Follow-up study of the implementation and impact of an ergonomic intervention University of Turku, Faculty of Medicine, Department of Clinical Medicine, Occupational Health Care Academic dissertation 2014.

[8] Cavallari, R., Martelli, F., Rosini, R., Buratti, C., \& Verdone, R. (2014). A survey on wireless body area networks: Technologies and design challenges. IEEE Communications Surveys \& Tutorials, 16(3), 16351657.

[9] Harper, G. 2002. Daily life in a nursing home. Has it changed in 25 years? Journal of aging studies 16 (4), 345-359

[10] Andersson, I., Pettersson, E. \& Sidenvall, B. 2007. Daily life after moving into a care home - experiences from older people, relatives and contact persons. Journal of Clinical Nursing 16 (9), 1712-1718.

[11] Bravell, M., Berg, S., Malmberg, B. \& Sundström, G. 2009. Sooner or later? A study of institutionalization on late life. Aging Clinical and Experimental Research 21 (4-5), 329-337.

[12] Mao, J. Y., Vredenburg, K., Smith, P. W., \& Carey, T. (2005). The state of user-centered design practice. Communications of the ACM, 48(3), 105-109.

[13] Klakegg, S., van Berkel, N., Visuri, A., Luo, C., Goncalves, J., Hosio, S., Huttunen, H-L. \& Ferreira, D. (2017). Informing Caregivers Through an Assistive Tool: An Investigation of Elderly Care Metrics. In Proceedings of the 31st British Human Computer Interaction Conference, BCS Learning and Development Ltd.

[14] Lamb, R., \& Kling, R. (2003). Reconceptualizing users as social actors in information systems research. MIS Quarterly, 197-236.

[15] Heikkilä, R \& Mäkelä, M (ed.). Success - RAI benchmarking, 15 years in Finland]. National Institute for Health and Welfare (THL). Report 9/2015. 182 pages. ISBN 978-952-302-477-9 (printed), ISBN 978-952302-478-6 (web), Helsinki Finland 2015. 
[16] Morris, J. N., Hawes, C., Fries, B. E., Phillips, C. D., Mor, V., Katz, S., .. \& Friedlob, A. S. (1990). Designing the national resident assessment instrument for nursing homes. The Gerontologist, 30(3), 293-307.

[17] Hawes, C. H., Morris, J. N., Phillips, C. D., Fries, B. E., Murphy, K., \& Mor, V. (1997). Development of the nursing home Resident Assessment Instrument in the USA. Age and Ageing, 26(suppl_2), 19-25.

[18] Hirdes, J. P., Smith, T. F., Rabinowitz, T., Yamauchi, K., Pérez, E., Telegdi, N. C., ... \& Fries, B. E. (2002). The resident assessment instrument-mental health (RAI-MH): Inter-rater reliability and convergent validity. The Journal of Behavioral Health Services and Research, 29(4), 419-432.

[19] Hirdes, J. P., Frijters, D. H., \& Teare, G. F. (2003). The MDS-CHESS scale: a new measure to predict mortality in institutionalized older people. Journal of the American Geriatrics Society, 51(1), 96-100.

[20] Björkgren, M. A., Häkkinen, U., Finne-Soveri, U. H., \& Fries, B. E. (1999). Validity and reliability of Resource Utilization Groups (RUG-III) in Finnish long-term care facilities. Scandinavian Journal of Social Medicine, 27(3), 228-234

[21] Mair, F. S., May, C., Finch, T., Murray, E., Anderson, G., Sullivan, F., . . . Epstein, O. (2007). Understanding the implementation and integration of e-health services. Journal of Telemedicine and Telecare, 13(suppl 1), 3637.

[22] DARGIE, W., JA POELLABAUER, C. Fundamentals of Wireless Sensor Networks: Theory and Practice. John Wiley and Sons, Inc., 2010.

[23] Ko, J., Lu, C., Srivastava, MB, Stankovic, JA, Terzis, A, \& Welsh, M. (2010). Wireless sensor networks for healthcare. Proceedings of the IEEE, 98(11), 1947-1960.

[24] Huttunen, H. L., Halonen, R., \& Koskimäki, H. (2017, September) Exploring use of wearable sensors to identify early symptoms of migraine attack. In Proceedings of the 2017 ACM International Joint Conference on Pervasive and Ubiquitous Computing and Proceedings of the 2017 ACM International Symposium on Wearable Computers (pp. 500-505). ACM.

[25] Chan, M., Campo, E., Esteve, D., \& Fourniols, J.-Y. Smart homes current features and future perspectives. Maturitas 64 1, 1 (2009), 90-97.

[26] Kumar, J. S., \& Patel, D. R. (2014). A survey on internet of things: Security and privacy issues. International Journal of Computer Applications, 90(11).

[27] Noro., A Finne-Soveri, H., Björkgren, M \& Vähäkangas, P., 2005. Quality and Productivity in Istitunional Care For Elderly Residents Benchemarking with RAI. National research and Development Care for Welfare and Health (STAKES), Helsinki 2005. ISBN 951-331772-2

[28] Sherwin, S. \& Winsby, M. 2010. A relational perspective on autonomy for older adults residing in nursing homes.Health Expectations 14, 182190. Report prepared U.S. Department of Health and Human Services. (2008). Physical Activity Guidelines Advisory Committee Report. Washington, DC, USA: U.S. Department of Health and Human Services;

[29] Schenk, L., Meyer, R. \& Behr, A. 2013. Quality of life in nursing homes: results of a qualitative resident survey. Qual Life Res 22, 2929-2938.
[30] Hirdes, J. P., Smith, T. F., Rabinowitz, T., Yamauchi, K., Pérez, E., Telegdi, N. C., ... \& Fries, B. E. (2002). The resident assessment instrument-mental health (RAI-MH): Inter-rater reliability and convergent validity. The Journal of Behavioral Health Services and Research, 29(4), 419-432.

[31] Räsänen, H. (2005). Henkilökunnan kokemuksia hoidon seurantajärjestelmän (RAI) käytettävyydestä vanhusten pitkäaikaishoidossa. Pro gradu-tutkielma. Terveyshallinnon ja-talouden laitos, Kuopion yliopisto.

[32] Ahmad, A., Teater, P., Bentley, T. D., Kuehn, L., Kumar, R. R., Thomas, A., \& Mekhjian, H. S. (2002). "Key attributes of a successful physician order entry system implementation in a multi-hospital environment." Journal of the American Medical Informatics Association, 9(1), 16-24.

[33] Larsson, S. \& Sjöblom, Y. (2010). Perspectives on narrative methods in social work research. International Journal of Social Welfare, 19, 272280.

[34] Neuman, W. L. (2014). What are the major types of social research? In: Social research methods: Qualitative and quantitative approaches. 7th ed. pp. 26-28, Pearson New International Edition, Essex, UK.

[35] Myers, M. D. (1997). Qualitative research in information systems. MIS Quarterly, 21(2), 241-242.

[36] Walsham, G., (2006). Doing interpretive research. European Journal of Information Systems, 15, 320-330.

[37] Rozzini, R., Frisoni, G. B., Bianchetti, A., Zanetti, O., \& Trabucchi, M. (1993). Physical performance test and activities of daily living scales in the assessment of health status in elderly people. Journal of the American Geriatrics Society, 41(10), 1109-1113. DOI: $10.1111 / \mathrm{j} .1532$ 5415.1993.tb06460.x

[38] Ministry of Social Affairs and Health, 2012. Act on care services for the elderly to ensure high standard of quality nationwid: http://stm.fi/en/artikkeli/-/asset_publisher/lagen-om-aldreservicetryggar-hogkvalitativa-tjanster-for-aldre-i-hela-landet

[39] Czaja, S. J., \& Lee, C. C. (2007). The impact of aging on access to technology. Universal Access in the Information Society, 5(4), 341.

[40] Steele, R., \& Clarke, A. (2012, July). A real-time, composite healthy building measurement architecture drawing upon occupant smartphonecollected data. In 10th International Healthy Buildings Conference.

[41] Timpano, K. R., Broman-Fulks, J. J., Glaesmer, H., Exner, C., Rief, W., Olatunji, B. O., ... \& Schmidt, N. B. (2013). A taxometric exploration of the latent structure of hoarding. Psychological assessment, 25(1), 194.

[42] Hopf, C. (2004). Qualitative interviews: An overview. A companion to qualitative research, 203-208.

[43] Neuman, W. L., \& Robson, K. (2014). Basics of social research. Pearson Canada.

[44] Kowal, S., \& O'connell, D. C. (2004). 5.9 The Transcription of Conversations. A Companion to, 248.

[45] Alan, H. F., Arnrich, B., Ersoy, C., \& Cinaz, B. (2014, April). Sensor Log: A mobile data collection and annotation application. In Signal Processing and Communications Applications Conference (SIU), 2014 22nd (pp. 1375-1378). IEEE. 